University of Nebraska - Lincoln

DigitalCommons@University of Nebraska - Lincoln

Sociology Department, Faculty Publications

Sociology, Department of

2020

\title{
A Comparison of Fully Labeled and Top-Labeled Grid Question Formats
}

Jolene Smyth

Kristen M. Olson

Follow this and additional works at: https://digitalcommons.unl.edu/sociologyfacpub

Part of the Family, Life Course, and Society Commons, Quantitative, Qualitative, Comparative, and Historical Methodologies Commons, and the Social Psychology and Interaction Commons

This Article is brought to you for free and open access by the Sociology, Department of at DigitalCommons@University of Nebraska - Lincoln. It has been accepted for inclusion in Sociology Department, Faculty Publications by an authorized administrator of DigitalCommons@University of Nebraska - Lincoln. 


\title{
A Comparison of Fully Labeled and Top-Labeled Grid Question Formats
}

\author{
Jolene D. Smyth and Kristen Olson
}

Department of Sociology, University of Nebraska-Lincoln, Lincoln, NE, USA

\section{Introduction}

The grid question format is common in mail and web surveys. In this format, a single question stem introduces a set of items, which are listed in rows of a table underneath the question stem. The table's columns contain the response options, usually only listed at the top, with answer spaces arrayed below and aligned with the items (Dillman et al. 2014).This format is efficient for respondents; they do not have to read the full question stem and full set of response options for every item in the grid. Likewise, it is space efficient for the survey researcher, which reduces printing and shipping costs in mail surveys and scrolling in web surveys.

However, grids also complicate the response task by introducing fairly complex groupings of information. To answer grid items, respondents have to connect disparate pieces of information in space by locating the position on the page or screen where the proper row (the item prompt) intersects with the proper column (the response option). The difficulty of this task increases when the respondent has to traverse the largest distances to connect items to response option

Published as Chapter 10 in Advances in Questionnaire Design, Development, Evaluation and Testing, First Edition. Edited by Paul C. Beatty, Debbie Collins, Lyn Kaye, Jose-Luis Padilla, Gordon B. Willis, and Amanda Wilmot.

Copyright (C) 2020 John Wiley \& Sons, Inc. Used by permission. 
labels (down and right in the grid) (Couper 2008; Kaczmirek 2011).This spatial connection task has to be conducted while remembering the shared question stem, perhaps after reading and answering multiple items. As a result, grid items are prone to high rates of item nonresponse, straightlining, and breakoffs (Couper et al. 2013; Tourangeau et al. 2004).

One way to possibly ease the burdens of grids in mail surveys is to repeat the response option labels in each row next to their corresponding answer spaces (Dillman 1978). Including response option labels near the answer spaces eliminates the need for vertical processing, allowing respondents to focus only on processing horizontally. However, fully labeling the answer spaces yields a more busy, dense display overall, which one can speculate might intimidate or overwhelm some respondents, leading them to skip the grid entirely.

In this chapter we report the results of a series of experimental comparisons of fully labeled versus top-labeled grid formats from national probability mail survey, a convenience sample of students in a paper-and-pencil survey, and a convenience sample in a webbased eye-tracking laboratory study. For each experiment we compare mean responses, inter-item correlations, item nonresponse rates, and straightlining. In addition, for the eye-tracking experiment we also examine whether the different grid designs impacted how respondents visually processed the grid items. For two of the experiments, we conduct subgroup analyses to assess whether the effects of the grids differed for high and low cognitive ability respondents. Our experiments are conducted using both attitude and behavior questions covering a wide variety of question topics and using a variety of types of response scales.

\subsection{Grid Items vs. Individual Items}

The tension between the benefits and difficulties of grids has spurred interest in the quality of grids as a survey measurement tool. The bulk of research on grids has focused on the effect of asking about multiple items when they are presented individually, each with its own question stem and response options, to when they are presented as a set of items in a grid with a shared question stem and response options. Most of these studies have been conducted in web surveys (for 
an exception, see Iglesias et al. 2001) and many confound the separation of items with paging such that in individual item conditions, each item is on a separate page of the web survey rather than displaying them as individual items on the same page (Callegaro et al. 2009; Couper et al. 2001; Peytchev 2007; Stern et al. 2015; Thorndike et al. 2009; Toepoel et al. 2005; Tourangeau et al. 2004. For exceptions, see Bell et al. 2001; Richards et al. 2016; and Yan 2005).

Generally, mean scores across items displayed individually versus in a grid are not significantly different from each other (Bell et al. 2001; Iglesias et al. 2001; Peytchev 2007; Toepoel et al. 2005; Yan 2005). However, a consistent trend is for items displayed in the grid format to have higher inter-item correlations (Callegaro et al. 2009; Couper et al. 2001; Peytchev 2007; Toepoel et al. 2005; Tourangeau et al. 2004; Yan 2005; for an exception, see Iglesias et al. 2001), but the differences only reached statistical significance in studies by Peytchev (2007) and Tourangeau et al. (2004). Thus, the magnitude of the difference in the correlational structure is usually not large. Although increased correlations may be thought to reflect improved data quality, Peytchev (2007) showed that the increased inter-item correlation in the grid format is likely due to correlated measurement error among grid items, probably caused by increased straightlining in the grid format, not to improved data quality. Factor loadings consistently do not differ across items in a grid versus individual items (Couper et al. 2001; Iglesias et al. 2001; Thorndike et al. 2009; Toepoel et al. 2005).Thus, compared to individual-item formats, the grid format appears to increase interitem correlations due to shared method variance, but has little effect on other measurement outcomes like means and factor loadings.

Other data quality indicators show somewhat larger differences across the grid and individual item treatments. A consistent trend is for the grid format to increase item nonresponse, both to the entire grid (Richards et al. 2016) and to individual items within the grid (Iglesias et al. 2001; Peytchev 2007; Richards et al. 2016; Toepoel et al. 2005; for an exception, see Callegaro et al. 2009) and more so in grids with more items (Toepoel et al. 2005). Additionally, Couper et al. (2001) found that the grid format decreased the rate of "don't know" and "not applicable" responses in a web survey where, importantly, a response was required for every item. The grid format increases nondifferentiation and/or straightlining (i.e. a satisficing response behavior 
in which respondents provide the same or nearly the same response for all items [Krosnick 1991]) (Richards et al. 2016; Stern et al. 2015; Tourangeau et al. 2004; but see Couper et al. 2001 for an exception). Finally, items tend to be answered more quickly when they are displayed in the grid format than in an individual-item format (Bell et al. 2001; Callegaro et al. 2009; Couper et al. 2001; Peytchev 2007; Stern et al. 2015; Thorndike et al. 2009; Toepoel et al. 2005; Tourangeau et al. 2004).

Empirically, there is no consistent difference in respondent perceptions of grids versus single items, with some evidence that individual items are preferred over grids. Although two studies suggest that respondents view the questionnaire as more difficult with grids, evaluate the layout of the questionnaire more poorly with grids, or prefer individual items over grid formats (Thorndike et al. 2009; Toepoel et al. 2005), and even more so the more items were included in each grid (Toepoel et al. 2005), two other studies found no such differences in similar respondent perceptions (Callegaro et al. 2009; Yan 2005).

Taken together, the existing literature suggests that the grid format has little impact on substantive results, but poses some difficulty for respondents as they answer grid items more quickly and are more likely to skip items within the grid, straightline, or give nondifferentiated answers. Moreover, respondents may find the grid format more difficult and prefer the individual-item format, but evidence on this is mixed.

\subsection{Dynamic Grid Features in Web Surveys}

Several studies have attempted to find ways to make grids easier for respondents and improve data quality. For example, Kaczmirek (2008) experimented with two dynamic grid design features in a web survey - a postselection feature where each item in the grid was grayed out when answered so respondents could more easily differentiate answered and unanswered items; and a preselection feature in which the row and column over which the mouse hovered were shaded, creating a cross-hair to help respondents ensure they were clicking the correct answer space. Both of these methods were compared to a control treatment utilizing a white background and no dynamic shading or interactivity. The dynamic designs did not change response distributions 
or response time, but did affect item nonresponse. Seventeen percent of respondents skipped at least one item in the control version. The cross-hair shading increased that rate to $19.4 \%$ (perhaps because it distracted respondents), but graying out answered items decreased the rate to $11.8 \%$. In a later study, Kaczmirek (2011) found similar results; preselection shading of table cells increased item nonresponse, but postselection graying of item rows decreased item nonresponse (and had no effect on nondifferentiation).

In another study, Couper et al. (2013) experimented with dynamic web design features in a matrix design where each row contained a type of fruit and two columns contained questions asking how often they eat each type of fruit and how much they usually eat. They tested graying out the "how much" question for fruits respondents reported never eating and graying out the entire row for fruits once both questions were fully answered. These dynamic features reduced item nonresponse and response time compared to a static version, but did not affect straightlining, which was rare in all of their treatments.

\subsection{Easing Grid Question Burden in Mail Surveys}

While such dynamic design features show promise, they cannot be used in mail surveys. However, the difficulty of responding to grids could be reduced in mail surveys by minimizing the need for respondents to work both horizontally and vertically to connect the relevant pieces of information. One way this might be done is by repeating the response option labels in every row of the grid as shown in the top panel of Figure 1 (Dillman 1978).

Several concepts from the vision sciences are relevant for understanding why this design may help respondents process grid items. First, according to the Gestalt psychologists' principle of continuity, items that appear to continue smoothly will be more easily perceived as belonging together (Ware 2004). In the fully labeled design, it should be much easier for respondents to group the items with the desired response option labels because the labels appear in the same horizontal line as the items. Respondents do not have to make the 90。 upward turn required to process the response options in the top-labeled grid. Moreover, during attentive visual processing, we only attend to a narrow slice of the entire visual field, called the useful field 


\section{Fully Labeled Grid}

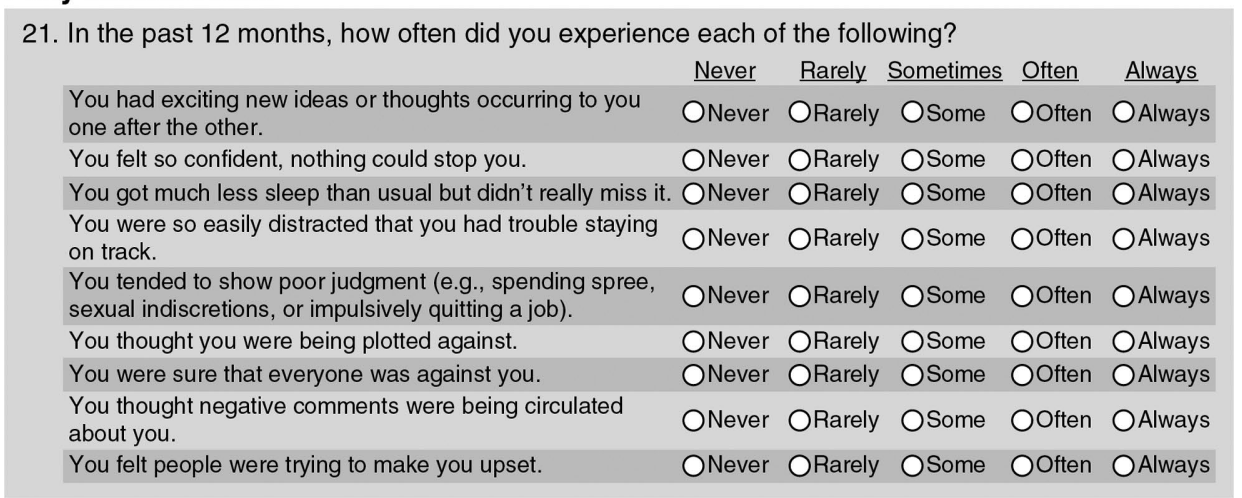

\section{Top Labeled Grid}

\begin{tabular}{|c|c|c|c|c|c|}
\hline \multicolumn{6}{|c|}{ 21. In the past 12 months, how often did you experience each of the following? } \\
\hline & Never & Rarely & Sometimes & $\underline{\text { Often }}$ & Always \\
\hline $\begin{array}{l}\text { You had exciting new ideas or thoughts occurring to you } \\
\text { one after the other. }\end{array}$ & 0 & 0 & 0 & $\overline{0}$ & 0 \\
\hline You felt so confident, nothing could stop you. & 0 & 0 & 0 & 0 & 0 \\
\hline You got much less sleep than usual but didn't really miss it. & $\mathrm{O}$ & O & O & $\mathrm{O}$ & O \\
\hline $\begin{array}{l}\text { You were so easily distracted that you had trouble staying } \\
\text { on track. }\end{array}$ & O & O & O & O & O \\
\hline $\begin{array}{l}\text { You tended to show poor judgment (e.g., spending spree, } \\
\text { sexual indiscretions, or impulsively quitting a job). }\end{array}$ & $\mathrm{O}$ & O & O & $\mathrm{O}$ & 0 \\
\hline You thought you were being plotted against. & $\mathrm{O}$ & O & O & 0 & $\mathrm{O}$ \\
\hline You were sure that everyone was against you. & 0 & $\mathrm{O}$ & $\mathrm{O}$ & $\mathrm{O}$ & $\mathrm{O}$ \\
\hline $\begin{array}{l}\text { You thought negative comments were being circulated } \\
\text { about you. }\end{array}$ & $\mathrm{O}$ & O & O & O & O \\
\hline You felt people were trying to make you upset. & 0 & 0 & 0 & 0 & 0 \\
\hline
\end{tabular}

Figure 1. Examples of top labeled and fully labeled grids.

of vision (Ware 2004). This includes the foveal view, which is made up two degrees of visual angle (i.e. 8-10 characters) and in which we can see very sharply, and an additional approximately $13 \circ$ of visual angle in which we can detect visual elements, but our vision is much less sharp (Ware 2004).The useful field of view gets smaller when visual information is dense (Ware 2004), as in the case of grid designs. Visual elements that appear outside the foveal view are more likely to be overlooked. Including the response option labels in every row of the grid should eliminate wide areas without visual elements, keeping the string of visual elements all within two degrees of visual angle of each other. This should make it easier for respondents to visually track across the row, moving from one visual element to the next without mistakenly jumping to a different row. In sum, in a fully labeled grid design, all of the information respondents need is contained in a single row of the grid in a continuous stream. 
Only two studies of which we are aware have previously examined fully labeled grids. In the first, Toepoel et al. (2005) examined the effects of presenting one item per screen versus grids consisting of 4 , 10 , or 40 items per screen. They fully crossed the 4,10 , and 40 items per-screen treatments with top versus fully labeled designs. The labeling had no effect in their study. However, their fully labeled design did not group the items, answer spaces, and response option labels together on one row as shown in Figure 1. Rather, they maintained a slightly more traditional grid design with the response option labels on the top row and the item and answer spaces one row below it for each item. Thus, each of their items appeared as a one-item top-labeled grid, and the need for vertical processing was not fully eliminated. Also, their respondents were web panel members who are likely very practiced at answering many types of survey questions, including grids.

In the second study, Smyth et al. (2014) compared item nonresponse and straightlining rates across top and fully labeled grid formats in a general population mail survey of Nebraska residents. With this sample and design, they found lower rates of item nonresponse in the fully labeled version, but no difference in straightlining rates. The current study attempts to replicate and extend this research.

\subsection{Understanding How Respondents Process Items in Grids}

Existing studies have compared response distributions, inter-item correlations, and a variety of data quality outcomes to understand how the grid format affects respondents' answers. These outcomes are indirect measures of underlying respondent processing. Eye-tracking methods provide a more direct measure of how respondents process survey questions by observing what they look at, for how long, and how their eyes move between visual elements (Galesic et al. 2008; Graesser et al. 2006; Redline and Lankford 2001). We take advantage of this capability to examine how respondents process grids. Insights from the eye-tracking study will allow us to better understand how grid format affects respondents and their answers. 


\subsection{Hypotheses}

We report the result of 12 experimental comparisons of top versus fully labeled grid designs in paper-and-pencil and web surveys. First we test for differences in the substantive answers respondents provide and in data quality indicators for these answers. Then, for one of these experiments, which was conducted in an eye-tracking laboratory, we test for differences in how respondents visually processed the two types of grids.

We do not expect the repetition of the response options to affect how respondents understand the items or formulate their answers for them. That is, repeating the response option labels should not affect comprehension, retrieval, or judgment. It could affect mapping, but we do not expect a consistent effect across respondents (i.e. no biasing effect). Thus, we hypothesize (H1) that there will be no difference across the top and fully labeled grids in means for individual items.

Correlations between items in grids can be affected through nondifferentiation, sometimes called straightlining. If, as the research shows, respondents are more likely to give nondifferentiated responses when items appear in grids, the correlations between those items will increase (i.e. correlated measurement error) (Peytchev 2007). It follows that any design feature that reduces nondifferentiation within grids should also reduce correlations among items. We expect fully labeling the grid will ease response burden in grids, reducing motivation to shortcut by straightlining or giving nondifferentiated responses. Thus, we hypothesize that the fully labeled grid will have (H2) lower rates of straightlining and $(\mathrm{H} 3)$ lower correlations between items than the top-labeled grid.

Because we expect the full labeling to reduce the difficulty of connecting information within the grid, we hypothesize (H4) that the fully labeled grid treatments will produce lower rates of item nonresponse than the top-labeled grid treatments. In particular, having the labels in each row should make it easier for respondents to answer without mistakenly getting off a row in either direction and inadvertently leaving items blank. However, while the fully labeled grid may be easier to complete (i.e. actual burden), it may initially be perceived as more burdensome because of its information-dense appearance. Thus, we hypothesize (H5) that the fully labeled grid will produce higher rates of 
respondents skipping over the entire grid (1.e. not answering any items within the grid).

In this study, we have a unique opportunity to evaluate how respondents are actually processing information in the grid through use of eye tracking. We anticipate that the full labeling should reduce or even eliminate the need for vertical processing. As a result, we hypothesize (H6) that compared to respondents in the top-labeled version, respondents in the fully labeled version will spend less time looking (i.e. fixation duration) at the response option labels at the top of the grid columns. In addition, we hypothesize ( $H 7$ ) that those in the fully labeled version will spend more time than those in the top-labeled version fixating on areas internal to the grid. With respect to entries (i.e. how many times respondents look at a specific area), we hypothesize (H8) that respondents in the fully labeled version will look at the top row of labels fewer times than those in the top-labeled version. We expect the manipulations here to impact the processing of the grid headings and answer spaces, but not the processing of the list of items in the leftmost column in the grid. Thus, we hypothesize there will be no difference across treatments in the amount of time $(\mathrm{H} 9)$ or number of gaze entries (H10) into the item prompts.

For reasons described earlier, responding to grid items is particularly difficult. We anticipate that it is even more difficult for those with low cognitive ability as their already limited cognitive resources are stretched further by the complicated demands of the grid format (Knäuper 1999; Krosnick 1991). As a result, we expect the full labeling to have a larger effect on these respondents. That is, we hypothesize that the full labeling will reduce item nonresponse rates (H11), straightlining (H12), and nondifferentiation (H13) further for low-cognitive-ability respondents than for high-cognitive-ability respondents and that the fully labeled grid will increase rates of skipping the entire grid more for low- than high-cognitive-ability respondents (H14).

\section{Data and Methods}

The comparisons between top and fully labeled grids in this chapter come from three different experiments in which we were able to test these ideas on both attitude and behavior items on a variety of topics 
and with a variety of types of response option scales. One experiment was conducted in the National Health, Wellbeing, and Perspectives Survey (NHWPS). NHWPS was a 12-page booklet questionnaire mail survey administered in summer 2015 with a random sample of 6000 addresses drawn from the USPS Postal Delivery Sequence File by Survey Sampling International. Households were randomly assigned to one of two experimental versions of the questionnaire ( $n=3000$ each) and asked to have the adult who would have the next birthday complete the survey. The American Association of Public Opinion Research (AAPOR) Response Rate 1 for NHWPS was $16.7 \%(n=1002)$ (AAPOR 2016) and did not differ across the two questionnaire versions (Version 1: $17.4 \%$, Version 2: $16.0 \%, \chi^{2}=2.15, p=0.143$ ). Respondent characteristics are shown in Table 1; they did not differ across the two experimental versions. Among the 77 questions in the NHWPS, seven were grid questions that were presented as top-labeled in one version and fully labeled in the other. ${ }^{1}$ These included 6 behavior questions and 1 attitude question with a range of from 5 to 17 items per grid and response scales containing 5 points. The general topics of the item prompts and response option constructs for each of these grids are summarized in Table 2. Table 2 also shows whether the response options were presented fully (e.g. "Strongly Agree") or in abbreviated form in the fully labeled version (e.g. "SA") for each grid question.

The second experiment, the "Getting Along" survey, was a paperand-pencil experiment carried out with a convenience sample of university students at a large Midwest university in Spring 2011. The survey contained 23 questions about student satisfaction with the university and diversity on campus. Two versions of the survey were developed with identical questions, but with one feature of each question experimentally varied across the versions. We focus here on three grid questions; one version had all three grids formatted as top-labeled, and the other fully labeled the grid questions. Two of the grids contained attitude questions; one asked about behaviors (see Table 2). Each of the grids contained five or six items. Prior to entering the classes, the two versions of the surveys were systematically arranged to alternate versions (fully-top-fully-top) in the set of surveys

1 The NHWPS experimental design included 3 questionnaire cover treatments, 3 incentive treatments, and 2 questionnaire version treatments for a total of 18 fully crossed treatments. Here we focus only on the two questionnaire version treatments. 
Table 1 Descriptive statistics for NHWPS, Getting Along, and Eye-Tracking studies overall and by version.

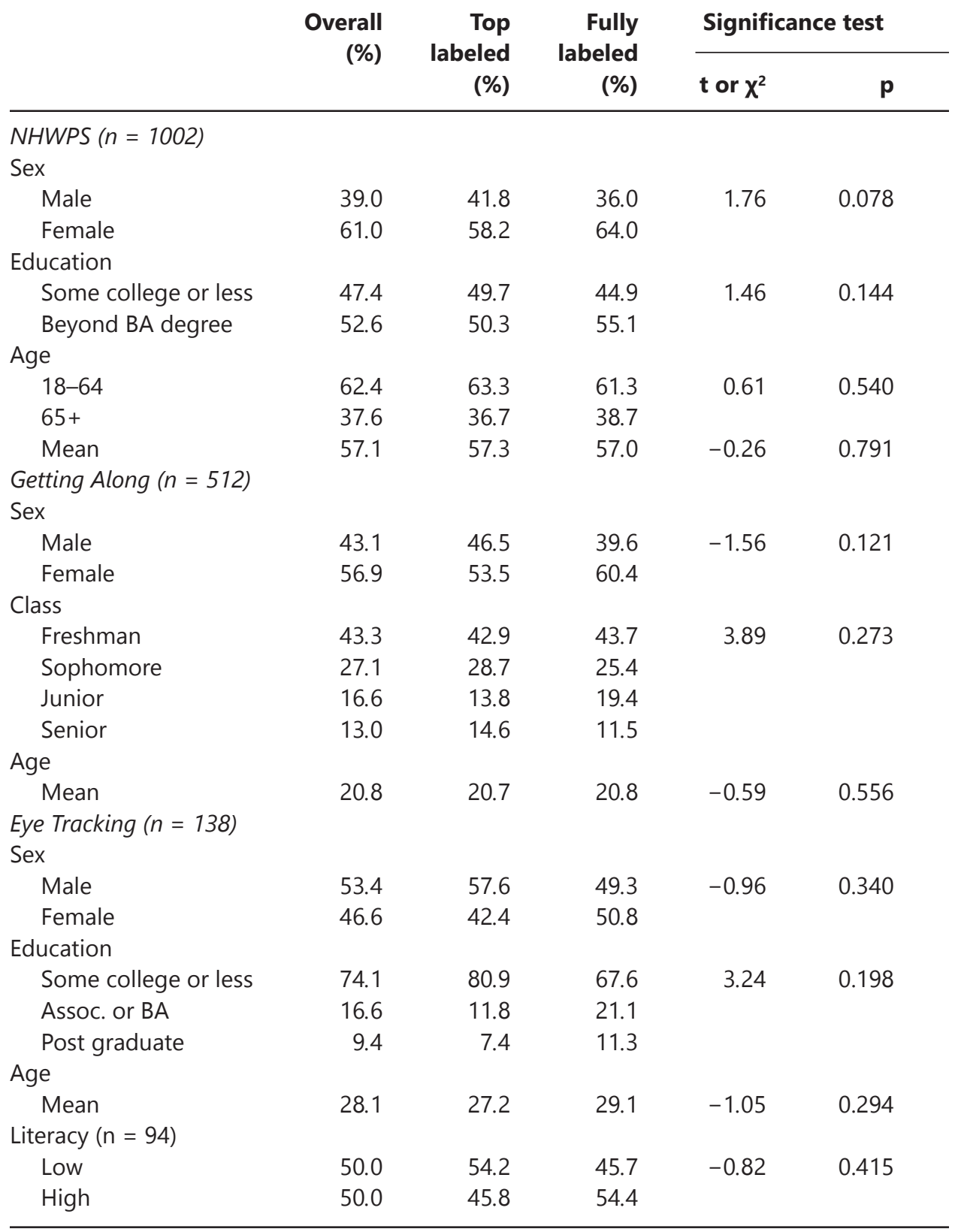

to distribute to a class so that quasi-random assignment could be achieved within classes. A member of the research team briefly introduced and handed out the survey to each class. Overall, 512 students completed the survey. Because this is a convenience sample and we do not have a count of how many students were in attendance on 
the days the survey was administered, we cannot calculate a response rate. Respondent characteristics did not differ across experimental versions for this experiment (Table 1).

The final experiment was a laboratory-based study with a convenience sample, using a web survey titled "Tourism and Recreation in Nebraska," containing 50 questions displayed across 44 web pages. For brevity, we refer to this study here as the "Eye-Tracking study." Two rounds of data collection occurred. The first round took place in Spring 2013 and included $n=47$ university student participants who each received a $\$ 5$ incentive for participation. The second round took place from December 2013 to April 2014 and included 120 general population participants who each received $\$ 22$ for participation. This resulted in a mix of 167 university students and general population members. In both rounds, participants were recruited through flyers, Craigslist advertisements, and word of mouth. Eligibility criteria for this study included being born in the United States, speaking English as a first language, and not wearing bifocals (a requirement for using the eye-tracking equipment). Participants were randomly assigned to receive one of two versions of the web questionnaire when they came to the laboratory in which features of individual questions, including grid labeling on two questions, were manipulated. After answering a brief in-person survey containing questions about technology use, literacy practices, and how they learned about the study, respondents completed the web survey while having their eye movements tracked. In the second round of this study (December 2013 to April 2014), respondents also completed the Wide Range Achievement Test 4 (WRAT4-Wilkinson and Robertson 2006), a literacy assessment, as part of the in-person survey. Because of technical difficulties, eyetracking data is not available for 28 cases. These are excluded from the analyses, resulting in an analytic sample size of 139. As with the other experiments, respondent characteristics did not differ across versions (Table 1). Table 2 provides details about the topics, response options, and question types for the grid questions in this experiment.

To record eye movements, we used Applied Science Laboratory's (ASL) D6 high-speed eye tracker, tracking eye movements at $120 \mathrm{~Hz}$ using a camera placed unobtrusively underneath the computer monitor. For this study, we defined a fixation as a gaze held for at least 60 milliseconds. This fixation length is shorter than that used other 
Table 2 Summary information about grid questions in three experiments.

\begin{tabular}{|c|c|c|c|c|}
\hline $\begin{array}{l}\text { Question number and } \\
\text { concept(s) measured } \\
\text { by item prompts }\end{array}$ & $\begin{array}{l}\text { Number } \\
\text { of item } \\
\text { prompts }\end{array}$ & $\begin{array}{l}\text { Type of } \\
\text { response } \\
\text { options }\end{array}$ & $\begin{array}{l}\text { Type of } \\
\text { question }\end{array}$ & $\begin{array}{l}\text { Type of } \\
\text { labelinga }\end{array}$ \\
\hline \multicolumn{5}{|l|}{ NHWPS } \\
\hline 9. Social support & 11 & Never/Always & Behavior & Full \\
\hline 12. Self-efficacy & 16 & Agree/Disagree & Attitude & Abb. \\
\hline 20. Depression and positive mental health & 17 & Never/Always & Behavior & Full \\
\hline 21. Mania and psychosis & 9 & Never/Always & Behavior & Full \\
\hline 22. Prosocial behaviors & 9 & Never/5 or More Times & Behavior & Full \\
\hline 23. Financial insecurity; time management & 14 & Never/Always & Behavior & Full \\
\hline 37. Alcohol consumption & 5 & Never $/ 5$ or More Times & Behavior & Full \\
\hline \multicolumn{5}{|l|}{ Getting Along } \\
\hline 5. Time in activities & 6 & 0 Hours/21+ Hours & Behavior & Full \\
\hline 10. Diversity commitment & 5 & Agree/Disagree & Attitude & Abb. \\
\hline 13. Diversity atmosphere & 6 & Satisfied/Dissatisfied & Attitude & Abb. \\
\hline \multicolumn{5}{|l|}{ Eye Tracking } \\
\hline 15. Satisfaction with leisure spaces & 6 & Satisfied/Dissatisfied & Attitude & Abb. \\
\hline 29. Time in leisure spaces & 7 & Never/Very Often & Behavior & Full \\
\hline
\end{tabular}

studies in the survey methodology field (e.g. Galesic et al. 2008; Galesic and Yan 2011), but is common practice in the vision sciences because people perceive information that influences their processing at this faster rate (Brunel and Ninio 1997; Sperling 1960). The eye tracker collects 120 measurements per second (e.g. $120 \mathrm{~Hz}$ ), making the data fairly unwieldy (i.e. large and nonrectangular). Because of this, we use interest areas to define important areas of the web survey screen and then aggregate eye-tracking data within the interest areas, described in detail shortly. The eye-tracking data is aggregated into summary measures for each of these areas, yielding information such as total duration of fixations in each interest area or the number of times a respondent's gaze entered each area.

A number of small changes were made to the questionnaire for the second round of the Eye-Tracking study to improve the eye-tracking measurements. The relevant change on the grid questions is that padding was added around items and response options to create more clear distinction between individual items. As a result, interest areas had to be redrawn. We account for the different-sized interest areas (in square pixels of the interest area) between the two eye-tracking rounds in the analyses. 


\subsection{Measures and Analytic Plan}

First we test for differences in mean responses to items in the grids using t-tests. We also use t-tests to test for differences in straightlining rates and nondifferentiation across the treatments. Our measure of strict straightlining is a dichotomous variable coded 1 if the respondent selected the same response option for every item they answered in the grid and coded 0 if they did not select the same response option for every item. Our measure of nondifferentiation is calculated as the standard deviation of each respondent's responses to all items within a grid. The mean of the respondent standard deviations are compared across the two treatments, where lower standard deviations are indicative of more nondifferentiation. Respondents who skipped over the entire grid are excluded from the straightlining and nondifferentiation analyses.

To examine differences in correlations across the two treatments, we start by testing for overall differences in the Pearson product-moment correlation matrix across treatments for each individual grid using a Jennrich chi-square test for equality of two correlation matrices (Jennrich 1970). For each grid, we then calculate the difference in each of the correlations between the top and fully labeled versions, testing for significant differences using Fisher's $Z$ transformation (Cohen et al. 2003, p. 49). We do not evaluate factor structure here because not all of the grids contain established scales or measure an underlying latent construct.

We examine nonresponse in two ways. First, we generate a variable coded 1 for respondents who skipped the entire grid and 0 for those who answered at least one item within the grid. We test for differences across grid treatments in the proportion of respondents who skipped the entire grid using both large sample chi-square tests and Fisher's exact $p$-values given the low prevalence of this outcome. Second, we generate a variable that is a count of the number of items within each grid that each respondent left blank. We examine the mean number of items left blank in each grid among all respondents, testing for differences across experimental treatments using t-tests. We then repeat this same comparison of the mean number of items left blank, but exclude those who skipped the entire grid. 
For the eye-tracking analyses, we start by defining the following interest areas, which are shown in Figure 2:

- The entire set of response option headings, labeled "Full Heading Area" in Figure 2

- Each individual response option heading, labeled "Individual Heading Areas" in Figure 2

- Headings and full answer area, labeled "Full Response Area with Headings" in Figure 2

- Each column of answer spaces within the grid, excluding the headings, labeled "Individual Response Columns" in Figure 2

- The column of item prompts, labeled "Item Prompts" in Figure 2

We define these interest areas separately for the top and fully labeled treatments. Because the spacing of the elements that made up the grids was different across the two treatments (e.g. the full labeling within the grid necessitated wider interest areas for the answer space columns) and because of the small spacing changes made between the two rounds of eye-tracking data collection, the size of the interest area varies slightly across rounds and across experimental treatments. This variation in area is accounted for in the analyses as described shortly.

After defining the interest areas, we then exported the total duration of all fixations each respondent made within each interest area and the number of times each respondent's gaze entered each interest area. We then log transform the duration variables, with zeros trimmed to the lowest observed value, to adjust for the typical skew of time-related data (Olson and Parkhurst 2013; Yan and Olson 2013). The duration analysis and the counts of gaze entries across experimental treatments use these areas as defined with one exception. For our duration analysis, to narrow down to just the full answer area without the headings, we subtract the "Full Headings Area" fixation duration from the "Full Answer Area with Headings" fixation duration. This subtraction is not possible for the entries outcome.

For each of the five resulting types of areas (full headings, individual headings, full answer area, individual answer columns, and item prompts), we test for differences across the experimental grid treatments by regressing (OLS) the log-transformed fixation duration 


\section{Full Headings Area}

15. Please indicate your overall satisfaction level with each of the following venues in Lincoln.

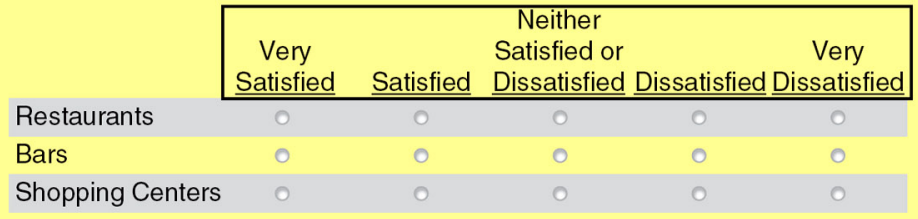

\section{Individual Headings Areas}

15. Please indicate your overall satisfaction level with each of the following venues in Lincoln.

\begin{tabular}{l|c|c|c|c|c|}
\hline & $\begin{array}{c}\text { Very } \\
\text { Satisfied }\end{array}$ & Satisfied & $\begin{array}{c}\text { Neither } \\
\text { Satisfied or } \\
\text { Dissatisfied }\end{array}$ & Dissatisfied & $\begin{array}{c}\text { Very } \\
\text { Dissatisfied }\end{array}$ \\
\cline { 2 - 4 } & 0 & 0 & 0 & 0 & 0 \\
Restaurants & 0 & 0 & 0 & 0 & 0 \\
Bars & 0 & 0 & 0 & 0 & 0 \\
Shopping Centers & 0 & 0 &
\end{tabular}

\section{Full Response Area with Headings}

15. Please indicate your overall satisfaction level with each of the following venues in Lincoln.

\begin{tabular}{l|ccccc|}
\cline { 2 - 6 } & $\begin{array}{c}\text { Very } \\
\text { Satisfied }\end{array}$ & Satisfied & $\begin{array}{c}\text { Neither } \\
\text { Satisfied or } \\
\text { Dissatisfied }\end{array}$ & $\begin{array}{c}\text { Dery } \\
\text { Ressatisfied }\end{array}$ \\
\cline { 3 - 5 } & 0 & 0 & 0 & 0 & 0 \\
Bars & 0 & 0 & 0 & 0 & 0 \\
Shopping Centers & 0 & 0 & 0 & 0 & 0 \\
Museums & 0 & 0 & 0 & 0 & 0 \\
Movie Theaters & 0 & 0 & 0 & 0 & 0 \\
Hotels & 0 & 0 & 0 & 0 & 0 \\
\hline
\end{tabular}

\section{Individual Response Columns}

15. Please indicate your overall satisfaction level with each of the following venues in Lincoln.

\begin{tabular}{|c|c|c|c|c|c|}
\hline & $\begin{array}{c}\text { Very } \\
\text { Satisfied } \\
\end{array}$ & Satisfied & $\begin{array}{c}\text { Neither } \\
\text { Satisfied or } \\
\text { Dissatisfied }\end{array}$ & Dissatisfied & $\begin{array}{c}\text { Very } \\
\text { Dissatisfied }\end{array}$ \\
\hline Restaurants & 0 & 0 & 0 & 0 & 0 \\
\hline Bars & 0 & 0 & 0 & 0 & 0 \\
\hline Shopping Centers & 0 & 0 & 0 & 0 & 0 \\
\hline Museums & 0 & 0 & 0 & 0 & 0 \\
\hline Movie Theaters & 0 & 0 & 0 & 0 & 0 \\
\hline Hotels & 0 & 0 & 0 & 0 & 0 \\
\hline
\end{tabular}

\section{Item Prompts}

15. Please indicate your overall satisfaction level with each of the following venues in Lincoln.

$$
\begin{array}{lll}
\text { Neither } & \text { Satisfied or } \quad \text { Very }
\end{array}
$$

\section{Satisfied Satisfied Dissatisfied Dissatisfied Dissatisfied}

\begin{tabular}{|l|}
\hline Restaurants \\
Bars \\
Shopping Centers \\
Museums \\
Movie Theaters \\
Hotels \\
\hline
\end{tabular}

$\begin{array}{ccccc}0 & 0 & 0 & 0 & 0 \\ 0 & 0 & 0 & 0 & 0 \\ 0 & 0 & 0 & 0 & 0 \\ 0 & 0 & 0 & 0 & 0 \\ 0 & 0 & 0 & 0 & 0 \\ 0 & 0 & 0 & 0 & 0\end{array}$

Figure 2. Illustration of interest areas from the Eye-Tracking study. 
variable on treatment (fully labeled $=1$, top labeled $=0$ ) and an area variable (square pixels in each interest area) that accounts for the differences in the size of interest areas across treatments and rounds of data collection. In the results tables, we report the raw mean durations for interpretability, but the significance tests are from the regression models that control for area. We use the same process to test for differences in the number of gaze entries across treatments, but use a negative binomial model for the significance tests rather than a linear regression model because our dependent variable is a count variable.

To test our hypotheses about the relationship between cognitive ability and our data quality outcomes, we conduct subgroup analyses using proxies for cognitive ability. ${ }^{2}$ In the NHWPS, we use age and education as proxies for cognitive ability, a practice that is consistent with previous literature (Knäuper 1999; Knäuper et al. 2007; Krosnick 1991; Krosnick and Alwin 1987). We test the main effects of age and education and interaction effects for both of these variables with the grid format on item nonresponse (full grid and number of items) and straightlining. Age and education are dichotomized (Age: $0=$ under age $65,1=65$ or older; Education: $0=\mathrm{BA}$ or higher, $1=$ some college or less). ${ }^{3}$

For the Eye-Tracking study, we do not have enough variation in age and education in this small sample to test our hypotheses (e.g. we only had one respondent age 65 or older). Thus, for this study we use literacy as our proxy for cognitive ability (Manly et al. 2004). Respondents' WRAT4 word reading and sentence comprehension scores were summed to calculate a composite score, which was then assigned a WRAT4 percentile rank (i.e. standardized to the US population) (see Wilkinson and Robertson 2006). The percentile ranks were then dichotomized with a median split into low literacy (coded 1) and high literacy (coded 0).

2 We do not conduct subgroup analyses with the Getting Along data because, by virtue of being a convenience sample of university students, there was very little heterogeneity in age or education in this study.

3 Missing data for age (18.2\% missing) and education (6.3\% missing) were multiply imputed 10 times using sequential regression methods in Stata 13.1 (ice procedure).We attempted to impute using all of the grid items, but the imputation did not converge so a more limited imputation was done that excluded the grid items. As a result, the association between the data quality outcomes and the subgroup indicators may be slightly attenuated. 


\section{Findings}

\subsection{Substantive Outcomes}

We start by assessing whether the top versus fully labeled grids produced different substantive responses $(\mathrm{H} 1)$. The NHWPS included 81 individual items (across seven grids), the Getting Along survey included 17 individual items (across three grids), and the Eye-Tracking study included 13 individual items (across two grids). The average absolute value of the difference in means between the top and fully labeled versions was 0.05 for the NHWPS, 0.06 for Getting Along, and 0.1 for the Eye-Tracking study. These are all very small differences. Across all three surveys (i.e. 111 individual items), only three of these mean differences were statistically significant at the $p<0.05$ level, and an additional four were moderately statistically significant. This is well within what we would expect by chance alone. Moreover, there is no clear trend in the direction of the differences; for $41 \%$ of items the fully labeled grid had a higher mean, for $51 \%$ of items it had a lower mean, and there was absolutely no difference for the remaining $8 \%$ of items (full results available from authors on request).Thus, our hypothesis (H1) that means would not differ across the top and fully labeled grids is supported.

We hypothesized that the fully labeled grid would have lower correlations between items than the top-labeled grid $(\mathrm{H} 3)$. When we compare the overall correlational structures of the two formats, we see significant differences $(p<0.05)$ in 8 of the 12 grids (see Table 3 ), indicating that the grid format did change how items within the grids were related to one another overall. We then tested for differences in correlations across the grid formats between each possible pair of items in each grid. With 111 items in all of the grids, this yielded 560 tests for differences in correlations. Of these, 46 (about 8\%) of the differences were statistically significant at a $p<0.05$ level. This is about what we would expect by chance alone. When we looked more closely at the correlations that were significantly different at a $p<0.05$ level across the grid treatments, we found that 44 of them were in the direction we would expect in both grid treatments based on the content of the items (e.g. we expect a positive correlation between items asking how often a respondent has people in their life with whom they 
Table 3 Results of correlation matrix structure comparisons.

\begin{tabular}{|c|c|c|c|c|c|c|c|}
\hline & \multirow{3}{*}{$\begin{array}{l}\begin{array}{l}\text { Overall } \\
\text { matrix } \\
\text { structure }\end{array} \\
\text { Jennrich } \chi^{2}\end{array}$} & \multirow{3}{*}{$\begin{array}{l}\text { \# of items } \\
\text { in grid }\end{array}$} & \multirow{3}{*}{$\begin{array}{l}\text { Number of } \\
\text { correlations } \\
\text { tested }\end{array}$} & \multirow{3}{*}{$\begin{array}{l}\text { Number of } \\
\text { tested } \\
\text { correlations } \\
\text { that were } \\
\text { sig. diff. }\end{array}$} & \multicolumn{3}{|c|}{ \# of sig. diff. correlations with... } \\
\hline & & & & & \multicolumn{2}{|c|}{$\begin{array}{l}\text { Correlations in } \\
\text { expected direction }\end{array}$} & \multirow{2}{*}{$\begin{array}{l}\text { Correlations in } \\
\text { unexpected } \\
\text { direction }\end{array}$} \\
\hline & & & & & $\begin{array}{l}\text { Strongest } \\
\text { in top } \\
\text { labeled }\end{array}$ & $\begin{array}{l}\text { Strongest } \\
\text { in fully } \\
\text { labeled }\end{array}$ & \\
\hline \multicolumn{8}{|l|}{ NHWPS } \\
\hline Q9 & $91.20^{* *}$ & 11 & 55 & 1 & 0 & 1 & 0 \\
\hline Q12 & $186.80^{\star * \star}$ & 16 & 120 & 12 & 4 & 6 & $2^{a}$ \\
\hline Q20 & $163.58^{*}$ & 17 & 136 & 5 & 2 & 3 & 0 \\
\hline Q21 & $82.55^{\star \star \star}$ & 9 & 36 & 5 & 3 & 2 & 0 \\
\hline Q22 & 36.54 & 9 & 36 & 2 & 1 & 1 & 0 \\
\hline Q23 & $126.47^{* *}$ & 14 & 91 & 12 & 3 & 9 & 0 \\
\hline Q37 & $24.46^{\star \star}$ & 5 & 10 & 2 & 0 & 2 & 0 \\
\hline \multicolumn{8}{|c|}{ Getting Along } \\
\hline Q5 & 17.57 & 6 & 15 & 1 & 1 & 0 & 0 \\
\hline Q10 & 12.65 & 5 & 10 & 0 & 0 & 0 & 0 \\
\hline Q13 & $39.95^{\star * *}$ & 6 & 15 & 3 & 3 & 0 & 0 \\
\hline \multicolumn{8}{|c|}{ Eye Tracking } \\
\hline Q15 & 12.99 & 6 & 15 & 1 & 1 & 0 & 0 \\
\hline Q29 & $25.73^{*}$ & 7 & 21 & 2 & 2 & 0 & 0 \\
\hline TOTAL & & 111 & 560 & 46 & 20 & 24 & 2 \\
\hline
\end{tabular}

$+p<0.100 ;{ }^{*} p \leq 0.050 ;{ }^{* *} p \leq 0.010 ;{ }^{* * *} p \leq 0.001$

a. These two comparisons had the strongest correlation in the top-labeled version.

have fun and with whom they enjoy doing things, and we expect a negative correlation between the statements, "I felt calm" and "I had trouble falling or staying asleep"). Of these, in 20 comparisons the correlation was strongest in the top-labeled format, and in 24 comparisons the correlation was strongest in the fully labeled format. Thus, while we know that the grid format produce significantly different correlational structures, our hypothesis that the fully labeled grid would reduce correlations between items $(\mathrm{H} 3)$ is not supported.

\subsection{Data Quality Indicators}

Next we examine straightlining (providing identical responses to all questions in the grid) and nondifferentiation (standard deviation in responses) within the grids ( $\mathrm{H} 2)$. For our strict straightlining measure, there was very little difference across the top and fully labeled grids. The difference in the percent who straightlined only reached 
statistical significance for one grid in the Eye-Tracking study (Q29), where $6 \%$ of respondents straightlined in the top-labeled version and none straightlined in the fully labeled version $(p<0.04)$. Among the remaining 11 grids across all 3 studies, there were no statistically significant differences, nor was there a clear trend in direction of effect. These findings are consistent with those reported by Smyth et al. (2014) and suggest that the fully labeled grid does not reduce straightlining, perhaps because straightlining was generally rare. The results of the nondifferentiation analyses corroborate these findings. Differences across the treatments in the mean standard deviation were statistically significant for only 3 of the 11 grids ( $p<0.058$ for all three). For two of these (Q22 and Q23 in the NHWPS), there was more nondifferentiation in the fully labeled grid; and for one (Q29 in the EyeTracking study) there was more nondifferentiation in the top-labeled version. Thus there is no clear difference between these two formats in straightlining or nondifferentiation $(\mathrm{H} 2)$.

Next we turn our attention to item nonresponse. We start by examining nonresponse to entire grids and find few differences across the two grid formats. In 7 of the 12 grids, the fully labeled format was skipped at higher rates than the top-labeled format as hypothesized $(\mathrm{H} 5)$, but only one of these differences was large enough to be statistically significant $(\mathrm{Q} 12$ in NHWPS, $\mathrm{p}=0.041)$. In the five remaining grids the differences were in the opposite direction, although also not statistically significant. Thus, fully labeling the grids does not appear to have a consistent negative impact on the rate of people skipping the grid entirely $(\mathrm{H} 5)$.

We next assess item nonresponse to the individual items within a grid. We hypothesized that the fully labeled grid would have less item nonresponse $(\mathrm{H} 4)$. We start by examining the mean number of items left blank among all respondents. We then exclude those who skipped the entire grid from the analysis, focusing only on those who answered at least one item in the grid. Among all respondents, the fully labeled version resulted in a higher mean number left blank in 7 of the 12 grids, but a lower mean number of items left blank in 5 grids. Moreover, only two of these differences were statistically significant. In Q12 in the NHWPS, the fully labeled version had a higher mean number of items left blank ( 0.53 vs. $0.23, t=-2.24, p=0.030$ ). In $Q 5$ of the Getting Along survey the 
fully labeled version had a lower mean number of items left blank (0.04 vs. $0.06, t=2.43, p=0.02$ ).

When those skipping the entire grid are excluded from the analyses, the results are similar in that the fully labeled grid format produced a higher mean number of items left blank in four of the grids and a lower mean number of items left blank in eight, but only one difference was large enough to be statistically significant (Q5 in the Getting Along survey, top-labeled $=0.06$ versus fully labeled $=0.04$, $t=2.43, p=0.020$ ). In fact, across all items, the average number of items left unanswered ranged from only 0.004 to 0.202 . Thus, the fully labeled grid format does not appreciably reduce item nonresponse compared to the top-labeled format $(\mathrm{H} 4)$.

\subsection{Eye-Tracking Analyses}

Next we turn our attention to how respondents visually process grid questions and the issue of whether processing patterns differ across the grid formats by examining the duration spent fixating on and the number of entries into key interest areas in the grid. Results for duration in question 15 can be seen in Table 4. On average, respondents spent 2.35 seconds fixating on the response option headings at the top of the grid, but looking at the two treatments separately reveals that those who answered in the fully labeled version spent $30 \%$ less time fixating on the headings ( 1.95 seconds) than those who answered in the top-labeled version (2.78 seconds, $t=2.96, p=0.004$ ), a finding that supports $\mathrm{H} 6 .{ }^{4}$ The pattern was in the same direction for question 29 (see Table 5), but the difference did not reach statistical significance. For both questions, this difference holds for each individual response option; that is, individual response option headings were fixated on less in the fully labeled than the top-labeled treatment with the differences reaching statistical significance for four of the five headings in question 15 and three of the five in question 29.

4 Response option labels were provided at the top of the grids in both treatments because for some questions the full label could not be used in the answer area of the fully labeled version due to space limits. As a result, the full label was provided at the top and an abbreviated label was provided within the grid. Respondents likely used the top labels to help understand the abbreviated labels in this version or simply because they appeared within the reading navigational path as respondents moved from the introductory stem to the specific items. 
Table 4 Mean number of seconds spent looking at response option headings and response option categories, Q15.

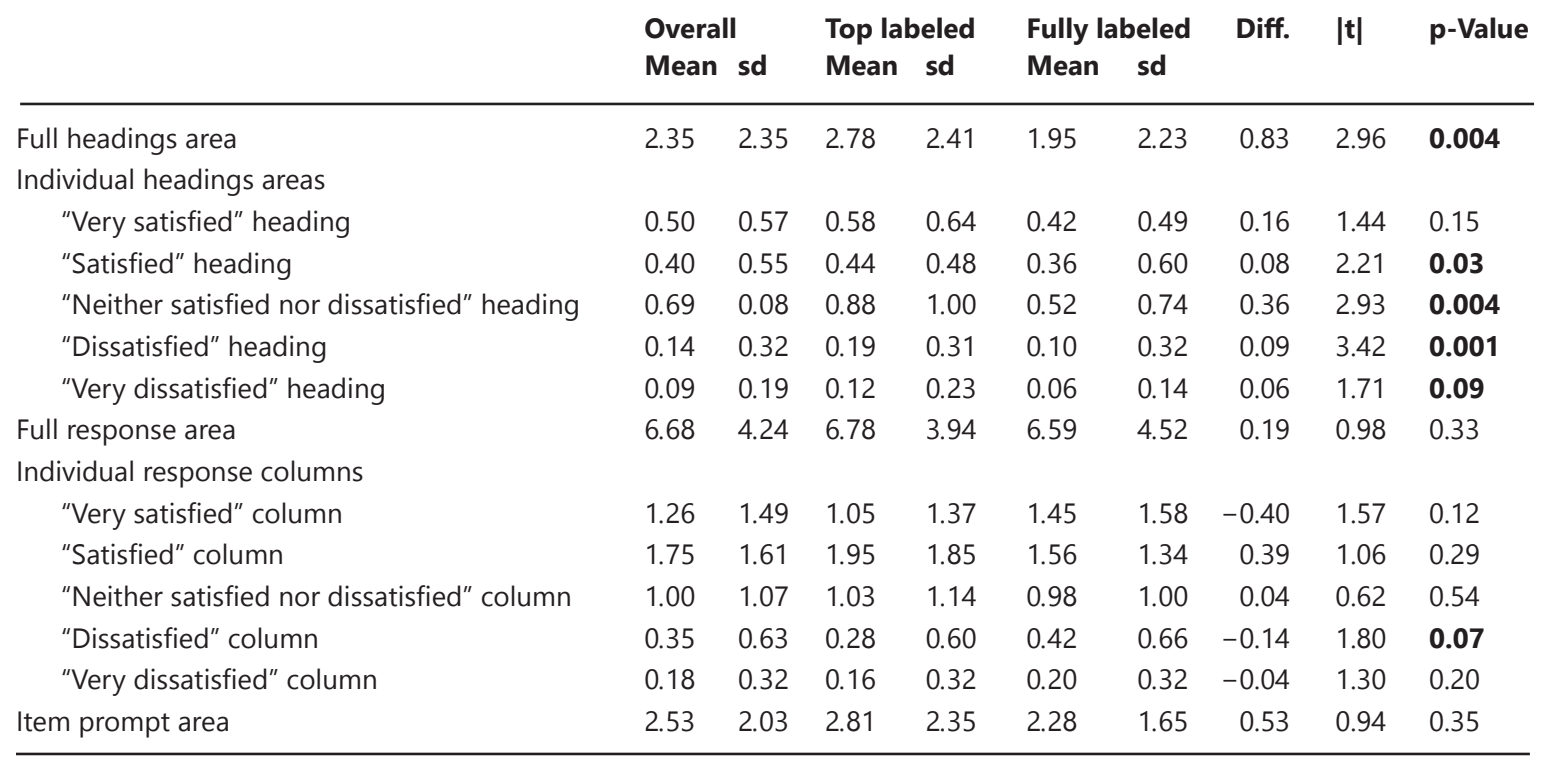

Q15 question wording: Please indicate your overall satisfaction level with each of the following venues in Lincoln. Overall $n=132$, top-labeled $n=63$, fully labeled $n=69$. Raw means and standard deviations are shown, but the statistical tests are estimated using log-transformed data with zeros trimmed to lowest observed value in a model controlling for the area (square pixels) in each interest area.

Table 5 Mean number of seconds spent looking at response option headings and response option categories, Q29.

\begin{tabular}{|c|c|c|c|c|c|c|c|c|c|}
\hline & \multirow{2}{*}{\multicolumn{2}{|c|}{$\begin{array}{l}\text { Overall } \\
\text { Mean sd }\end{array}$}} & \multicolumn{2}{|c|}{ Top labeled } & \multicolumn{2}{|c|}{ Fully labeled } & \multirow[t]{2}{*}{ Diff. } & \multirow[t]{2}{*}{$|\mathbf{t}|$} & \multirow[t]{2}{*}{ p-Value } \\
\hline & & & Mean & sd & Mean & sd & & & \\
\hline Full heading area & 0.96 & 1.26 & 1.20 & 1.51 & 0.75 & 0.93 & 0.45 & 1.09 & 0.28 \\
\hline \multicolumn{10}{|l|}{ Individual headings areas } \\
\hline "Very satisfied" heading & 0.22 & 0.34 & 0.27 & 0.42 & 0.18 & 0.24 & 0.09 & 0.63 & 0.53 \\
\hline "Satisfied" heading & 0.19 & 0.36 & 0.25 & 0.45 & 0.13 & 0.23 & 0.13 & 1.99 & 0.05 \\
\hline "Neither satisfied nor dissatisfied" heading & 0.24 & 0.44 & 0.35 & 0.55 & 0.14 & 0.28 & 0.21 & 3.72 & 0.00 \\
\hline "Dissatisfied" heading & 0.11 & 0.20 & 0.15 & 0.22 & 0.08 & 0.18 & 0.06 & 2.07 & 0.04 \\
\hline "Very dissatisfied" heading & 0.08 & 0.21 & 0.09 & 0.21 & 0.07 & 0.22 & 0.02 & 0.90 & 0.37 \\
\hline Full response area & 7.12 & 4.43 & 7.25 & 4.58 & 7.00 & 4.31 & 0.25 & 0.63 & 0.53 \\
\hline \multicolumn{10}{|l|}{ Individual response columns } \\
\hline "Very satisfied" column & 0.74 & 1.00 & 0.44 & 0.49 & 1.00 & 1.25 & -0.56 & 0.87 & 0.39 \\
\hline "Satisfied" column & 1.37 & 1.66 & 1.20 & 1.90 & 1.52 & 1.40 & -0.31 & 0.54 & 0.59 \\
\hline "Neither satisfied nor dissatisfied" column & 1.47 & 1.35 & 1.51 & 1.34 & 1.43 & 1.36 & 0.08 & 0.69 & 0.49 \\
\hline "Dissatisfied" column & 1.08 & 1.19 & 0.99 & 1.23 & 1.17 & 1.16 & -0.18 & 0.01 & 1.00 \\
\hline "Very dissatisfied" column & 0.81 & 1.06 & 0.78 & 1.00 & 0.84 & 1.11 & -0.06 & 0.44 & 0.66 \\
\hline Item prompt area & 4.68 & 3.62 & 5.23 & 3.53 & 4.19 & 3.66 & 1.04 & 1.24 & 0.89 \\
\hline
\end{tabular}

Q29 question wording: How often do you use each of the following recreational facilities in Lincoln? Overall $n=132$, toplabeled $n=63$, fully labeled $n=69$. Raw means and standard deviations are shown, but the statistical tests are estimated using log-transformed data with zeros trimmed 
The analysis of fixation duration on individual headings also reveals that respondents spent more time fixating on the middle response option heading than any of the other response option headings. If all five response options in these grids were processed equally, we would expect respondents to spend about $20 \%$ of their fixation duration on each response option heading, but on Q15, respondents spent 38\% of their total fixation duration fixating on the middle response option heading. The percent of time spent on each of the other response options ranged from 5-27\%. This apparent anchoring happened in both grid treatments, with those in the top-labeled version spending $40 \%$ of their fixation duration on the middle response option and those in the fully labeled version spending slightly less at $36 \%$ of their total time. The same pattern occurs in Q29 where overall respondents spent about $29 \%$ of their total fixation duration fixating on the middle response option, but the values are $32 \%$ for the top-labeled version and $23 \%$ for the fully labeled version. These findings suggest that the fully labeled version changes anchoring on the middle response option heading, perhaps because it encourages more direct left-toright processing as respondents proceed from the items into the response options (i.e. processing the scale points in order). ${ }^{5}$

Next we look at response options and answer spaces within the grid, excluding the column headings. The difference in fixation duration in the response area between the top and fully labeled treatments was very small and failed to reach statistical significance in both questions ( $p>0.05)$. Moreover, the direction of the difference was opposite of what we hypothesized. Thus there is no support for our hypothesis that respondents would spend more time fixating in the response area in the fully labeled version (H7). Examination of individual columns within the response area reveals no significant differences, and no clear pattern of direction of effects. Thus, respondents do not differ in fixation duration in the response area of the grids across the two formats. There was also no significant difference in fixation duration on the item prompts themselves (i.e. the leftmost column) for either question in this experiment (supporting H9).

5 In other eye-tracking work, we have observed about a quarter of respondents process scales by starting in the middle of a horizontally displayed scale rather than at the first point in the scale. Those who do this are much more likely to then select the midpoint as their response. 
In addition to hypothesizing that respondents to the fully labeled grid treatment would spend less time overall looking at the column headings, we also hypothesized that they would look up to the heading area fewer times than those in the top-labeled treatment $(\mathrm{H} 8)$. Our results generally support this hypothesis. Table 6 shows that on average, respondents' gaze entered the grid heading area 11 times for question 15, but that the mean number of entries differed significantly by grid type. In the top-labeled treatment, respondents' gaze entered the heading area an average of 12.8 times compared to 9.5 times in the fully labeled treatment $(t=1.87, p=0.06)$. Moreover, each individual heading interest area was entered more times in the top than the fully labeled treatment, with two of the five differences reaching statistical significance. For question 29 (Table 7), the difference in the mean number of entries into the entire heading area did not reach statistical significance, although it was in the hypothesized direction. However, three of the five individual heading interest areas had a statistically lower mean number of gaze entries in the fully labeled treatment than the top-labeled treatment and a fourth was moderately statistically significant.

Further analysis revealed no significant difference for either question in the mean number of gaze entries into any of the interest areas capturing the individual response option columns. Nor were there any significant differences across the two treatments in the mean number of times respondents' gaze entered the interest area for the item prompts themselves (supporting $\mathrm{H} 10$ ).

\subsection{Subgroup Analyses}

For the NHWPS we also examine whether levels of each of our data quality indicators were affected by age or education overall as well as whether each of these proxies for cognitive ability moderated the effects of the experimental treatment.

As Table 8 shows, education was not associated with the likelihood of skipping the entire grid or the mean number of items left blank when those who skipped the grid are included in the analyses. When those who skipped the grid entirely are excluded from the analyses, education is significantly associated with the mean number of items missing for three of the seven items (Q20, Q22, and Q23), such that 
Table 6 Number of entries into response option headings and response option categories, Q15.

\begin{tabular}{|c|c|c|c|c|c|c|c|c|c|}
\hline & \multicolumn{2}{|c|}{$\begin{array}{l}\text { Overall } \\
\text { Mean sd }\end{array}$} & \multicolumn{2}{|c|}{ Top labeled } & \multicolumn{2}{|c|}{ Fully labeled } & Diff. & $|z|$ & p-Value \\
\hline Full heading area & 11.09 & 10.32 & 12.83 & 11.02 & 9.51 & 9.44 & 3.32 & 1.87 & 0.06 \\
\hline \multicolumn{10}{|l|}{ Individual headings areas } \\
\hline "Very satisfied" heading & 3.79 & 3.70 & 4.32 & 3.91 & 3.30 & 3.47 & 1.01 & 1.52 & 0.13 \\
\hline "Satisfied" heading & 3.24 & 3.26 & 3.75 & 3.14 & 2.78 & 3.32 & 0.96 & 1.48 & 0.14 \\
\hline "Neither satisfied nor dissatisfied" heading & 4.10 & 4.65 & 4.95 & 5.03 & 3.32 & 4.16 & 1.63 & 2.09 & 0.04 \\
\hline "Dissatisfied" heading & 1.36 & 2.29 & 1.70 & 2.48 & 1.06 & 2.07 & 0.64 & 1.91 & 0.06 \\
\hline "Very dissatisfied" heading & 0.92 & 1.57 & 1.11 & 1.57 & 0.74 & 1.56 & 0.37 & 1.26 & 0.21 \\
\hline \multicolumn{10}{|l|}{ Individual response columns } \\
\hline "Very satisfied" column & 10.83 & 6.74 & 11.43 & 7.12 & 10.29 & 6.38 & 1.14 & 1.06 & 0.29 \\
\hline "Satisfied" column & 10.08 & 8.16 & 10.48 & 7.05 & 9.72 & 9.09 & 0.75 & 0.44 & 0.66 \\
\hline "Neither satisfied nor dissatisfied" column & 6.19 & 7.46 & 6.44 & 7.64 & 5.96 & 7.33 & 0.49 & 0.55 & 0.58 \\
\hline "Dissatisfied" column & 2.75 & 4.33 & 2.44 & 4.08 & 3.03 & 4.56 & -0.58 & 0.87 & 0.38 \\
\hline "Very dissatisfied" column & 1.51 & 3.27 & 1.54 & 4.11 & 1.48 & 2.30 & 0.06 & 0.85 & 0.40 \\
\hline Item prompt area & 13.73 & 8.34 & 13.71 & 8.97 & 13.75 & 7.78 & -0.04 & 0.01 & 0.99 \\
\hline
\end{tabular}

Q15 question wording: Please indicate your overall satisfaction level with each of the following venues in Lincoln. Overall $n=132$, top-labeled $n=63$, fully labeled $n=69$. Statistical tests estimated using a negative binomial model to account for the count data comparing fully labeled to top labeled (reference category) and controlling for the number of square pixels in the interest area.

Table 7 Number of entries into response option headings and response option categories, Q29.

\begin{tabular}{|c|c|c|c|c|c|c|c|c|c|}
\hline & $\begin{array}{l}\text { Overal } \\
\text { Mean }\end{array}$ & & $\begin{array}{l}\text { Top lab } \\
\text { Mean }\end{array}$ & $\begin{array}{l}\text { peled } \\
\text { sd }\end{array}$ & $\begin{array}{l}\text { Fully la } \\
\text { Mean }\end{array}$ & $\begin{array}{l}\text { beled } \\
\text { sd }\end{array}$ & Diff. & $|z|$ & p-Value \\
\hline Full heading area & 6.64 & 5.99 & 7.30 & 6.12 & 6.03 & 5.85 & 1.27 & 0.23 & 0.66 \\
\hline \multicolumn{10}{|l|}{ Individual headings areas } \\
\hline "Very satisfied" heading & 2.12 & 2.09 & 2.17 & 2.08 & 2.07 & 2.11 & 0.10 & 1.51 & 0.13 \\
\hline "Satisfied" heading & 1.83 & 2.05 & 2.17 & 2.30 & 1.51 & 1.75 & 0.67 & 1.92 & 0.06 \\
\hline "Neither satisfied nor dissatisfied" heading & 2.24 & 2.68 & 3.05 & 3.04 & 1.51 & 2.06 & 1.54 & 3.46 & 0.00 \\
\hline "Dissatisfied" heading & 1.20 & 1.81 & 1.43 & 1.82 & 1.00 & 1.79 & 0.43 & 1.65 & 0.10 \\
\hline "Very dissatisfied" heading & 0.79 & 1.69 & 1.14 & 2.11 & 0.46 & 1.11 & 0.68 & 2.20 & 0.03 \\
\hline \multicolumn{10}{|l|}{ Individual response columns } \\
\hline "Very satisfied" column & 9.52 & 5.95 & 9.16 & 5.74 & 9.86 & 6.16 & -0.70 & 0.62 & 0.54 \\
\hline "Satisfied" column & 10.54 & 8.06 & 10.81 & 8.83 & 10.29 & 7.35 & 0.52 & 1.52 & 0.13 \\
\hline "Neither satisfied nor dissatisfied" column & 10.15 & 9.49 & 10.49 & 10.06 & 9.84 & 9.01 & 0.65 & 1.43 & 0.15 \\
\hline "Dissatisfied" column & 7.20 & 7.02 & 6.87 & 6.49 & 7.51 & 7.51 & -0.63 & 0.07 & 0.95 \\
\hline "Very dissatisfied" column & 3.95 & 4.77 & 4.32 & 5.74 & 3.61 & 3.70 & 0.71 & 0.67 & 0.50 \\
\hline Item prompt area & 18.14 & 12.06 & 17.92 & 9.93 & 18.33 & 13.79 & -0.41 & 0.16 & 0.87 \\
\hline
\end{tabular}

Q29 question wording: How often do you use each of the following recreational facilities in Lincoln? Overall $n=132$, top-labeled $n=63$, fully labeled $n=69$. Statistical tests estimated using a negative binomial model to account for the count data comparing fully labeled to top labeled (reference category) and controlling for the number of square pixels of the interest area. 
Table 8 Regression results predicting data quality outcomes with education and age for NHWPS grid questions.

Question number

\begin{tabular}{|c|c|c|c|c|c|c|c|}
\hline & \multicolumn{7}{|c|}{ Question number } \\
\hline & Q9 & Q12 & Q20 & Q21 & Q22 & Q23 & Q37 \\
\hline \multicolumn{8}{|c|}{ Skipping entire grid (odds ratios) } \\
\hline Education $(<\mathrm{BA})$ & 1.51 & 0.57 & 0.64 & 0.78 & 0.72 & 0.68 & 0.90 \\
\hline Age $(65+)$ & 1.75 & 1.38 & $2.19 *$ & $2.42^{* *}$ & $2.14^{*}$ & $2.19 *$ & 1.06 \\
\hline \multicolumn{8}{|c|}{ Mean number left blank (all Rs) (incidence rate ratios) } \\
\hline Education $(<\mathrm{BA})$ & 1.49 & 1.07 & 0.94 & 0.86 & 1.04 & 0.86 & 0.81 \\
\hline Age $(65+)$ & 1.98 & 1.45 & $2.09 *$ & $2.03+$ & $2.16^{*}$ & $2.02+$ & 1.42 \\
\hline \multicolumn{8}{|c|}{ Mean number of items left blank (excluding skipped entire grid) (incidence rate ratios) } \\
\hline Education $(<\mathrm{BA})$ & 1.58 & 1.71 & $2.28^{*}$ & 1.14 & $2.99 * *$ & $2.37^{*}$ & 0.91 \\
\hline Age $(65+)$ & $2.18+$ & 1.41 & $2.29 * *$ & 0.87 & $2.58^{* \star}$ & 1.77 & 4.61 \\
\hline \multicolumn{8}{|c|}{ Straightlining (odds ratios) } \\
\hline Education $(<\mathrm{BA})$ & 0.93 & 4.10 & - & 1.17 & $12.66^{* * *}$ & - & $1.43^{* *}$ \\
\hline Age $(65+)$ & $0.58^{* *}$ & 1.54 & - & 0.69 & 1.06 & - & $2.07^{\star \star *}$ \\
\hline \multicolumn{8}{|c|}{ Nondifferentiation (coefficients) } \\
\hline Education $(<\mathrm{BA})$ & 0.03 & $-0.09 * * *$ & $-0.06^{* *}$ & 0.02 & $-0.22^{* * *}$ & $-0.16^{* * *}$ & $-0.15^{\star * *}$ \\
\hline Age $(65+)$ & $0.04+$ & $-0.10^{* * *}$ & 0.01 & -0.02 & $0.08 *$ & $0.14^{* * *}$ & $-0.15^{\star * \star}$ \\
\hline
\end{tabular}

Only estimates for education and age are shown here. All models also controlled for experimental version. $+p \leq 0.100 ;{ }^{*} p \leq 0.050 ;{ }^{* *} p \leq 0.010 ;{ }^{* * *} p \leq 0.001$.

individuals with some college or less have twice the rate of missing values in these grids than those with a BA or more. In addition, for two of the seven grids (Q22 and Q37), those with low education were more likely to straightline; and for five of the seven (Q12, Q20, Q22, Q23, and Q37), those with lower education had lower mean standard deviations across items within single grids (i.e. more nondifferentiation). Contrary to our hypothesis, there were no significant interactions between education and grid format for any of these outcomes ( $\mathrm{H} 11, \mathrm{H} 12, \mathrm{H} 13, \mathrm{H} 14$ - results available upon request).

The direct effects of age were also largely as hypothesized for the item nonresponse outcomes, but varied for straightlining (see Table 8).Those age 65 and older were twice as likely to skip the entire grid on four of the seven grid items (Q20, Q21, Q22, and Q23) and left items left blank at a rate twice that of younger respondents on two of the seven grids when those who skipped entire grids were excluded from the analysis (Q20 and Q22). For two items, Q9 and Q37, respondents age 65 or older differed from their younger counterparts in their 
probability of straightlining, although the direction differed over the two grids. Older respondents had higher mean standard deviations across items (i.e. less nondifferentiation) for two grids (Q22 and Q23) and lower average standard deviations across items within grids for two of the grids (i.e. more nondifferentiation - Q12 and Q37). Contrary to our hypothesis, there were no significant interactions between age and the experimental treatments for any of these outcomes $(H 11$, $\mathrm{H} 12, \mathrm{H} 13, \mathrm{H} 14$ - results available upon request).

Finally, for the Eye-Tracking study, we were able to examine the association of the data quality outcomes with respondent literacy as well as whether literacy interacted significantly with grid format. Literacy did not have any statistically significant main or interaction effects for any of the outcomes for either grid in this study $(\mathrm{H} 11, \mathrm{H} 12, \mathrm{H} 13, \mathrm{H} 14)$.

\section{Discussion and Conclusions}

The grid format has a reputation for being difficult for respondents, and while findings are mixed, there is evidence that this format reduces response quality (i.e. increases item nonresponse and straightlining and increases correlated measurement error, thus impacting inter-item correlations; Couper et al. 2013; Peytchev 2007; Tourangeau et al. 2004). Several studies have demonstrated how dynamic feedback features can be used in web surveys to reduce these negative effects (Couper et al. 2013; Kaczmirek 2008, 2011), but no such features are available to assist respondents answering grid questions in paper-and-pencil surveys. We compared a traditional top-labeled grid design to a fully labeled grid design that was intended to reduce respondent burden by eliminating vertical processing and allowing respondents to process on a single continual horizontal row.

Overall, we found very few differences between the top and fully labeled grid designs on either responses or data quality indicators. There was no meaningful difference in mean responses to individual items or in straightlining, nondifferentiation, skipping the entire grid, or skipping items within the grid. These results held regardless of cognitive ability of respondents. That is, the grid treatments had virtually the same effect on the younger and older respondents, less- and more-educated respondents, and low- and high-literacy respondents. 
We did find, however, that the two grid formats produced different correlation matrix structures, but there is no clear evidence in our analyses as to why the correlations differed or which, if either, is better. We also could not look at whether data quality was improved or reduced when these same items were asked as individual items rather than in a grid. Future research should replicate these experiments and extend them by examining factor loadings for underlying traits in grid items and predictive validity of the grid items to try to ascertain the veracity and importance of the differences we found. Future research should also compare these treatments to questions asked as individual items rather than in a grid, and should continue to explore other design features that might reduce the difficulty of grids.

While the responses and data quality were very similar across the two grid formats, the type of labeling did seem to impact the way respondents processed the items. The eye-tracking analyses revealed that the fully labeled format required less vertical processing, as measured by the amount of time respondents spent looking at the column headings and the number of times their eyes moved to the headings. This reduced time spent looking at the headings in the fully labeled version was not made up by time looking at the answer area as there was no significant difference in the amount of time respondents spent looking at the answer area across the two treatments. Thus, respondents appeared to have visually navigated the headings and answer space more quickly in the fully labeled version without impacting their responses or data quality in any appreciable way. In addition, this format appeared to reduce the amount of anchoring on the middle response option (although this did not seem to affect endorsement of the middle option; analyses not shown). Moreover, the two formats did not differ in how much time or how many times respondents look at the item prompts.

The fact that the fully labeled grid format did not impact responses or diminish data quality suggests that it may be fruitful to explore whether this format can be used in web surveys with mobile devices. A major problem with the display of grid questions on small mobile devices is that respondents can typically see the item prompts if they hold their device vertically or the response option headings if they hold it horizontally, but can rarely see both at once. This results in increasing need to scroll vertically and horizontally to try to connect 
both pieces of the question. Most software that optimizes web surveys for mobile devices deals with this challenge by removing the grid format altogether and displaying the items one-by-one on mobile devices; however, this risks giving respondents on computers and mobile devices considerably different stimuli and may introduce device effects. Fully labeled grids, provided the labels are fairly short, may provide an alternative whereby the grid format can be maintained across both devices, but scrolling can be minimized and limited to only one direction (i.e. horizontal).

In sum, we come away from these experiments cautiously optimistic. The fully labeled grid design did not have the positive impacts we expected it to have on data quality indicators, but it may have reduced respondent burden by reducing reliance on the column headings. At the same time, more work is needed to understand the implications of the differences in correlation matrix structure that we found across the two treatments in terms of predictive validity, factor structure (where appropriate), and other relational measures.

Acknowledgments NHWPS data collection was supported by funding provided by the Office of Research and Economic Development and the Department of Sociology at the University of Nebraska-Lincoln. Data processing and analysis was supported in part by funds provided to the University of Nebraska-Lincoln under a Cooperative Agreement with the USDA-National Agricultural Statistics service supported by the National Science Foundation National Center for Science and Engineering Statistics [58-AEU-5-0023 Jolene Smyth \& Kristen Olson PIs]. The Eye-Tracking study was supported by funds provided by the Department of Sociology and the College of Arts and Sciences at the University of Nebraska-Lincoln. The authors would like to acknowledge and thank Josey Elliot for her efforts in in developing and fielding the Getting Along survey and Amanda Ganshert for assistance with data analysis.

\section{References}

AAPOR. (2016). Standard definitions: Final dispositions of case codes and outcome rates for surveys. https://www.aapor.org/AAPOR Main/media/ publications/Standard-Definitions20169theditionfinal.pdf

Bell, D.S., Mangione, C.M., and Kahn, C.E. (2001). Randomized testing of alternative survey formats using anonymous volunteers on the World Wide Web. Journal of the American Medical Informatics Association 8 (6): 616-620.

Brunel, N. and Ninio, J. (1997). Time to detect the difference between two images presented side by side. Cognitive Brain Research 5: 273-282. 
Callegaro, M., Shand-Lubbers, J., and Dennis, J.M. (2009). Presentation of a single item versus a grid: Effects on the vitality and mental health scales of the SF-36v2 health survey. American Association for Public Opinion Research Conference, Hollywood Florida.

Cohen, J., Cohen, P., West, S.G., and Aiken, L.S. (2003). Applied Multiple Regression/ Correlation Analysis for the Behavioral Sciences, 3e. New York: Routledge.

Couper, M.P. (2008). Designing Effective Web Surveys. New York: Cambridge University Press.

Couper, M.P., Traugott, M.W., and Lamias, M.J. (2001).Web survey design and administration. Public Opinion Quarterly 65 (2): 230-253.

Couper, M.P., Tourangeau, R., Conrad, F.G., and Zhang, C. (2013).The design of grids in web surveys. Social Science Computer Review 31 (3): 322-345.

Dillman, D.A. (1978). Mail and Telephone Surveys: The Total Design Method. New York: Wiley.

Dillman, D.A., Smyth, J.D., and Christian, L.M. (2014). Internet, Phone, Mail, and Mixed-Mode Surveys: The Tailored Design Method. Hoboken, NJ: Wiley.

Galesic, M. and Yan, T. (2011). Use of eye tracking for studying survey response processes. In: Social and Behavioral Research and the Internet: Advances in Applied Methods and Research Strategies (eds. M. Das, P. Ester and L. Kaczmirek), 349-370. New York, NY: Taylor and Francis Group.

Galesic, M., Tourangeau, R., Couper, M.P., and Conrad, F.G. (2008). Eye-tracking data new insights on response order effects and other cognitive shortcuts in survey responding. Public Opinion Quarterly 72 (5): 892-913.

Graesser, A.C., Cai, Z., Louwerse, M.M., and Daniel, F. (2006). Question understanding aid (QUAID): a web facility that tests question comprehensibility. Public Opinion Quarterly 70 (1): 3-22.

Iglesias, C.P., Birks, Y.F., and Torgerson, D.J. (2001). Improving the measurement of quality of life in older people: the York SF-12. QJM 94 (12): 695-698.

Jennrich, R.I. (1970). An asymptotic $\chi 2$ test for the equality of two correlation matrices. Journal of the American Statistical Association 65 (330): 904-912.

Kaczmirek, L. (2008). Human-survey interaction: Usability and nonresponse in online surveys. Doctoral dissertation. University of Mannheim, Germany. https://ub-adoc.bib.uni-mannheim.de/2150/1/kaczmirek2008.pdf

Kaczmirek, L. (2011). Attention and usability in internet surveys: effects of visual feedback in grid questions. In: Social and Behavioral Research and the Internet: Advances in Applied Methods and Research Strategies (eds. M. Das, P. Ester and L. Kaczmirek), 191-214. New York: Routledge.

Knäuper, B. (1999).The impact of age and education on response order effects in attitude measurement. Public Opinion Quarterly 63: 347-370.

Schwarz, N., Park, D., and Fritsch, A. (2007).The perils of interpreting age differences in attitude reports: question order effects decrease with age. Journal of Official Statistics 23 (4): 515-528.

Krosnick, J.A. (1991). Response strategies for coping with the cognitive demands of attitude measures in surveys. Applied Cognitive Psychology 5: 213-236. 
Krosnick, J.A. and Alwin, D.F. (1987). An evaluation of a cognitive theory of response-order effects in survey measurement. Public Opinion Quarterly 51: 201-219.

Manly, J.J., Byrd, D., Touradji, P. et al. (2004). Literacy and cognitive change among ethnically diverse elders. International Journal of Psychology 39: 47-60.

Olson, K. and Parkhurst, B. (2013). Collecting paradata for measurement error evaluations. In: Improving Surveys with Paradata: Analytic Uses of Process Information (ed. F. Kreuter), 43-72. Hoboken, NJ: Wiley.

Peytchev, A.A. (2007). Participation decisions and measurement error in web surveys. Doctoral dissertation. University of Michigan.

Redline, C.D. and Lankford, C.P. (2001). Eye-movement analysis: A new tool for evaluating the design of visually administered instruments (paper and web). American Association for Public Opinion Research Conference, Montreal, Quebec, Canada.

Richards, A., Powell, R., Murphy, J. et al. (2016). Gridlocked: the impact of adapting survey grids for smartphones. Survey Practice 9 (3).

Smyth, J.D., Olson, K., and Kasabian, A. (2014). The effect of answering in a preferred mode versus a non-preferred survey mode on measurement. Survey Research Methods 8 (3): 137-152.

Sperling, G. (1960).The information available in brief visual presentations. Psychological Monographs 74 (11),Whole No. 498.

Stern, M., Sterrett, D., Bilgen, I. et al. (2015). The Effects of Grids on Web Surveys Completed with Mobile Devices. Paper Presented at the American Association for Public Opinion Research Conference. Florida: Hollywood.

Thorndike, F.P., Carlbring, P., Smyth, F.L. et al. (2009).Web-based measurement: effect of completing single or multiple items per webpage. Computers in Human Behavior 25 (2): 393-401.

Toepoel, V., Das, J.W.M., and van Soest, A.H.O. (2005). Design of web questionnaires: A test for number of items per screen. CentER Discussion Paper; vol. 2005-114. Tilburg University. https://pure.uvt.nl/ws/portalfiles/ portal/776381/114.pdf

Tourangeau, R., Couper, M.P., and Conrad, F. (2004). Spacing, position, and order interpretive heuristics for visual features of survey questions. Public Opinion Quarterly 68 (3): 368-393.

Ware, C. (2004). Information Visualization: Perception for Design. San Francisco, CA: Morgan Kaufmann.

Wilkinson, G.S. and Robertson, G.J. (2006). WRAT4 Wide Range Achievement Test Professional Manual. Lutz, FL: Psychological Assessment Resources Inc.

Yan, T. (2005). Gricean effects in self-administered surveys. Doctoral dissertation. University of Maryland, College Park, Maryland.

Yan, T. and Olson, K. (2013). Analyzing paradata to investigate measurement error. In: Improving Surveys with Paradata: Analytic Uses of Process Information (ed. F. Kreuter), 73-96. Hoboken, NJ: Wiley. 